\title{
ENFRENTANDO POETAS, PERSEGUINDO PEIXES: SOBRE ETNOGRAFIAS E ENGAJAMENTOS
}

Carlos Emanuel Sautchuk João Miguel M. Sautchuk

[...] participando nessas atividades, [o antropólogo] capta pela ação tanto como pelo ouvido e a vista o que sucede à sua volta.

E. Evans-Pritchard (2002:80).

Um dos principais desenvolvimentos da antropologia nas últimas décadas foi a ideia da constituição das relações a partir da ação, o que levou à emergência de um leque de formulações diversas em torno das noções de prática ou de experiência, afirmando-se por diferentes vias que as ações não são mera decorrência de normas e conhecimentos explícitos. Esse tipo de postura orientou também algumas reflexões sobre a etnografia, como aquela em torno da noção de participação observante, evocando a imersão do pesquisador nas relações pesquisadas, seja no sentido de um engajamento político ou corporal. ${ }^{1}$

Debateremos questões relativas a este campo a partir das pesquisas realizadas pelos dois autores em situações distintas, que envolvem conjuntos bastante complexos de habilidades e de saberes. Trata-se do repente nordestino, prática de poesia improvisada estudada por João Sautchuk (2012), e de duas modalidades de pesca na região do estuário do rio Amazonas captura do pirarucu com arpão e pesca costeira embarcada - pesquisadas por Carlos Sautchuk (2007). Mais do que apresentar os sistemas de práticas e conhecimentos (o que faremos aqui de maneira bastante resumida), trataremos neste artigo das estratégias etnográficas empregadas nesses dois casos.

Ambos adotamos como principal abordagem etnográfica, explícita e conscientemente, o intuito de aprender, de nos engajarmos efetivamente no desenrolar das atividades pesquisadas. O objetivo inicial era propiciar uma aproximação com certos aspectos que pareciam menos enfatizados em 
grande parte dos estudos sobre repentistas ou pescadores. Em uma palavra, motivou-nos a tentativa de evitar recair em alguns lugares comuns na constituição da dimensão empírica em nossos respectivos campos etnográficos. Nos estudos sobre repentistas, pareceu necessário escapar da centralidade conferida à análise de conteúdo de representações linguísticas e construções melódicas, já que o objetivo era compreender o improviso. No caso da pesca, partiu-se de uma insatisfação, por um lado, com as descrições formalistas de ações e artefatos e, por outro, com as análises que tratam a relação com os ambientes e os ofícios como resultado da objetivação de relações econômicas, preceitos ou saberes abstratos.

Num primeiro momento, essa postura conduziu-nos à percepção relativamente comum de que, se as características fundamentais de valores, significados, disposições e técnicas constitutivas dos sistemas de práticas e conhecimentos ganham vida sem a necessidade de verbalização e são arredias às reflexões conscientes e às exposições narrativas, a inserção pela própria prática nesses sistemas poderia abrir ao antropólogo a oportunidade de estabelecer um contato mais complexo e efetivo com esses universos. A ideia de prática não remete aqui, que fique bem claro, a qualquer acepção sobre mimese do nativo ou sobre "tornar-se um deles". Trata-se, isto sim, de proporcionar relações que não restrinjam a empiria etnográfica ou o fazer antropológico ao que pode ser visualmente percebido ou verbalmente comunicado. Afinal, procuramos caminhar justamente na direção de uma aproximação etnográfica que evitasse reproduzir o contraste entre saber e fazer, intelecto e ação.

É importante ressaltar que não nos alinhamos à defesa de um conhecimento calcado na experiência individual do etnógrafo e tampouco no menosprezo da interação verbal em prol da prática ou da corporalidade. Tomamos a noção de experiência (e sua inspiração fenomenológica) como indicação e postura, não como objetivo ou resultado último da interação etnográfica. Como veremos mais adiante, consideramos o engajamento etnográfico como uma busca pela qualificação das relações estabelecidas pelo etnógrafo nos termos locais. Tais precisões, que serão discutidas mais a fundo na parte final do artigo, devem-se ao fato de que as abordagens que adotamos não são oriundas primariamente de convicções teóricas em defesa da experiência, mas de certa sensibilidade etnográfica característica dos campos temáticos com os quais dialogamos.

Os estudos sobre técnica, assim como aqueles voltados à etnomusicologia, em que pese a grande variedade de suas propostas epistêmicas, consolidaram o hábito de acionar o engajamento prático enquanto estratégia de pesquisa. Tradição esta que não foi concebida primordialmente como 
princípio ou afirmação de ordem teórica, mas como resultado do imperativo de integrar-se à situação pesquisada de tal modo que fosse possível a aproximação com certo plano de relações que dificilmente se revela à observação ou às interações verbais.

Em estudos que tratam de técnicas ou da chamada cultura material, a experiência prática é tomada como um fator que contribui para a compreensão etnográfica do próprio processo técnico. Alguns pesquisadores deixam inclusive transparecer o papel dos erros em que incorrem ao praticar certas operações como fator revelador. Chamoux (1978:84; ver também Chamoux 1981) refere-se à sua tentativa de praticar a tecelagem entre uma população do México como permeada de equívocos que elucidaram passos importantes e ignorados sobre a relação entre alguns gestos e a compleição final do desenho. Lemonnier (1975:162) relata algo semelhante ao descrever sua pesquisa numa salina, atentando, por exemplo, para os complexos procedimentos de manipulação da pá. Ele defende o papel fundamental da experimentação nos estudos sobre técnica de modo geral, porém ressalta a sofisticação dos aprendizados, chamando a atenção para as diferenças fundamentais entre o envolvimento do etnógrafo e o daqueles que ele pesquisa, sublinhando com isto o risco etnocêntrico do pesquisador ao inserir-se nas atividades, supor-se artesão, caçador ou salineiro (Lemonnier 1992:27). Já Ingold, para mostrar o valor central da habilidade com o laço entre os criadores de rena, descreve a ocasião da separação coletiva dos animais, em que cada proprietário deve laçar e retirar os seus em meio a uma multidão de animais e criadores, e completa: "uma mão inexperiente com o laço (como foi a do antropólogo, no meu caso) pode causar caos" (1993a:112). Nestes exemplos, o equívoco marca e qualifica uma diferença, assumindo por isto mesmo um papel heurístico de primeira ordem.

Outros mencionam o valor do engajamento prático enquanto esforço para desempenhar a tarefa técnica ao modo local, enfatizando a importância de uma aproximação, ainda que relativa. Citemos três exemplos de estudos sobre caça. Laura Rival (1996:149), ao notar que o conhecimento dos caçadores não era verbalizado, passou a acompanhar as caçadas (sem efetuá-las), articulando sua experiência de deslocamento pela floresta com as conversas informais entre os caçadores durante e depois da atividade. Encontrava, nessas ocasiões, não descrições da caça, mas debates de estratégias, podendo através da compreensão deles acessar sentidos mais profundos da atividade. Sobre seu trabalho de campo, voltado para a relação entre os Achuar e o meio ambiente, Descola (1994 [1986]:133) ressalta que o principal material etnográfico não era propriamente a comunicação verbal, mas as técnicas de relação com a "natureza", acessadas por meio de uma participação progressiva: "quando o 
jardim parece ter revelado os seus mistérios, é tempo de realizar a primeira incursão à floresta ameaçadora e tentar caçar por si mesmo". Esta "modesta experiência pessoal" (1994 [1986]:307) foi responsável por importantes revelações sobre as diversas formas de relação entre o caçador e suas presas. Assim também, Silverwood-Cope percebeu que seguir os caçadores em sua atividade seria o melhor caminho para compreender a relação dos Maku com a floresta. Mas, para acompanhar efetivamente, pareceu-lhe necessário aprender a atividade. Desajeitado no início, ele se tornaria versado na arte cinegética, ainda que empregando arma de fogo, e não zarabatana:

Aprendi tudo o que pude, cada detalhe em seguir, atrair, cercar e matar animais de caça. Aprendi como cada técnica se baseava num conhecimento específico do comportamento do animal em questão. Após um ano, já se notava uma mudança fundamental nas atitudes dos Makú para comigo (Silverwood-Cope 1990:33-34).

Contudo, provavelmente a demonstração mais taxativa dessa forma de aproximação empírica por meio do engajamento esteja na obra de Marcel Mauss. A pertinência da prática para tratar dos assuntos relativos à dimensão cinestésica aparece no seu famoso texto sobre as técnicas do corpo (Mauss 2003), ainda que de modo subjacente e pouco lembrado. Contrastivamente, observemos que, noutros escritos, Mauss ocupa a posição de narrador distanciado, que se coloca como observador e analista, mas não como participante. É significativo que, justamente no texto sobre técnicas do corpo, ele lance mão a todo instante de sua vivência pessoal como fonte das informações - seja sua incapacidade de nadar como as gerações mais novas, a forma como ensinou aos seus recrutas determinada marcha, ou ainda como foi levado a correr de modo peculiar, com os punhos colados ao corpo (Mauss 2003:402-404).

Entretanto, não se deve seguir adiante sem uma percepção mais clara do argumento central de Mauss nesse texto. Ao falar da técnica sem instrumentos, Mauss adota a concepção de que ela não é exterior, mas sim intrínseca ao próprio homem, à sua corporalidade, definidora mesmo da humanidade (Vatin 2004). Sendo assim, os instrumentos não seriam exatamente extensões, mas a continuidade do próprio corpo, justamente porque Mauss não aborda a técnica enquanto ação sobre a realidade exterior discreta, mas enquanto conjuntos de relações que envolvem o homem (Mauss 2009). Não esqueçamos, aliás, que As técnicas do corpo é tido como um texto inspirador, não apenas para o que se tem chamado de antropologia do corpo, mas também para abordagens voltadas ao estudo das técnicas, notadamente na França (Sigaut 1994; Bert 2012; Sautchuk, C. 2014). 
Nesta direção, Leroi-Gourhan (2004:13), o principal seguidor das ideias maussianas sobre a tecnologia, defende vigorosamente a experimentação do etnógrafo como forma de ultrapassar descrições formalistas, exteriores às operações. Apenas praticando seria viável passar a uma compreensão das relações criadoras e dinâmicas entre gestos, artefatos e materiais, ou melhor, do conjunto de movimentos que expande e conecta a ação humana, transcendendo tanto os limites do seu corpo anatômico quanto uma visão inerte e objetificada dos artefatos. A partir desse preceito é que Warnier $(1999,2001)$, por exemplo, viria a elaborar uma aproximação teórico-metodológica da cultura material que concede valor central ao engajamento subjetivo, inclusive do etnógrafo.

Esse apanhado permite a constatação de que, sem constituir-se necessariamente enquanto proposta teórica, ou melhor, teorizada, o engajamento do etnógrafo tem sido acionado sistematicamente como forma de abordagem empírica quando o foco são as técnicas ou a cultura material. Algo muito semelhante ocorre também no campo da etnomusicologia, onde o aprendizado da arte que se analisa é uma estratégia de pesquisa adotada pelo menos desde a década de 1960, quando Hood (1960) propôs o desenvolvimento de uma "bimusicalidade" pelo pesquisador "ocidental" para compreender tradições musicais "orientais". Segundo este autor, para se distanciar da escala temperada de 12 notas e dos padrões estéticos do canto ocidental, o etnomusicólogo deveria procurar reproduzir não apenas os padrões sonoros, mas também os gestos, os movimentos e as atitudes corporais que são próprios da execução musical e afetam diretamente seus resultados sonoros.

Contudo, as reflexões de Hood estão nitidamente marcadas por uma ideia de etnomusicologia como musicologia de tradições musicais não ocidentais - ou seja, como uma musicologia de outras músicas que não a música erudita ocidental, origem, motivo e base dos pressupostos analíticos da própria musicologia enquanto disciplina. A proposta de bimusicalidade continua a nortear pesquisas etnomusicológicas e, em muitos casos, reproduz ainda hoje o dilema analisado por Menezes Bastos (1995) entre o estudo musicológico detalhado de uma tradição musical tomado como fim em si mesmo e a análise antropológica que ignora ou omite a dimensão performativa das práticas e teorias musicais. Por outro lado, alguns desenvolvimentos da proposta da bimusicalidade apontam para a superação de tal dilema na medida em que privilegiam a investigação das práticas musicais como via para a compreensão das dinâmicas da vida social.

Já Silverman (1995) procura afirmar como instrumento de pesquisa a performance da arte estudada fora de seu contexto social original, por exemplo, a apresentação pela etnomusicóloga de canções búlgaras em cafés nova-iorquinos. Nesse sentido, a ênfase da bimusicalidade recai sobre 
o desenvolvimento de uma destreza acurada na prática que se quer etnografar. Porém, nesses moldes, tende a isolar a prática musical em questão de seu contexto de interações sociais. Por outro lado, Titon (1995) ressalta que a bimusicalidade envolve o aprendizado de uma tradição musical com os mestres dessa tradição, e isso, mais do que a performance, pode mostrar ao pesquisador valores coletivos, padrões estéticos e papéis dos indivíduos numa prática musical e em sua reprodução.

Baily (2001) argumenta que apenas por meio da execução musical se pode apreender elementos essenciais da música em questão, pois se percebe a estrutura em seu modo prático, operacional. Quer dizer, passa-se a entender a música em termos daquilo que se faz e do que se deve saber fazer, e se chega, por meio da prática, aos conhecimentos operacionais que diferenciam o músico do ouvinte (e também do pesquisador) sem habilidades específicas. Ou ainda, a pergunta sobre como determinados músicos ou artistas fazem o que fazem não pode ser respondida somente em termos de regras e padrões estéticos. No mesmo sentido, Brinner (1995) entende que a explicação do "como se faz" passa por influências situacionais, tomadas de decisão em fração de segundos, e uma diversidade de capacidades incorporadas e automatizadas difíceis de verbalizar. Além disso, o fazer musical, em especial em conjunto, é fundamentalmente uma interação orientada por diferenças de papéis sociais, conhecimentos musicais internalizados, como escalas e padrões rítmicos, e traquejo em um sistema comunicativo próprio dos músicos em suas apresentações, o que inclui deixas que um músico indica ao outro (Brinner 1995).

Seeger (2004), em seus estudos sobre os Suyá, propõe uma antropologia musical que, para além do estudo da música enquanto produto da cultura, procura investigar como as práticas e os conhecimentos musicais participam da própria construção e interpretação dos processos e das relações conceituais e sociais. Por exemplo, ao cantar junto com os homens suyá, Seeger cometia erros que motivavam risos e gracejos dos seus mestres e parceiros de canto. Isto porque o canto em uníssono era uma atividade lúdica masculina que contribuía para a construção da solidariedade entre os homens da aldeia, assim como as refeições em conjunto e as conversas na casa dos homens.

Tendo sido acolhido pelos Suyá como aprendiz no que se refere não apenas à música, mas também à própria subsistência, Seeger $(1980,2004)$ mostra que aprender e fazer música junto a eles foi revelador sobre os significados da música na sociedade suyá e seu lugar na vida cerimonial. Em outras palavras, a inserção prática se integrou a uma estratégia de pesquisa empírica, o que pôde caracterizar o estudo da música como abordagem para o estudo da vida social como um todo. 
De modo geral, tais estudos etnomusicológicos mostram que o aprendizado de uma habilidade, de um fazer, permite sistematizar conhecimentos analíticos sobre as competências exigidas por uma atividade musical ou poético-musical. Em relação à reprodução das destrezas artísticas, a prática permite discernir elementos que devem ser interiorizados, automatizados na e pela prática (como o ritmo poético no repente nordestino), e outros que são mais acessíveis ao aprendizado por ensinamentos verbais (como algumas minúcias das regras de rima que os repentistas devem seguir). Oferece também oportunidade de executar estratégias de criação e apresentação e uma noção da hierarquia entre cada tipo de maestria no desempenho da arte. Além disso, essa estratégia de pesquisa coloca o pesquisador em contato com formas de aprendizado peculiares de um contexto social e situa o antropólogo internamente ao sistema de relações etnografado, permitindo conhecer um senso prático constituído por essas relações e constitutivo delas.

Situada esta breve resenha a respeito da inserção prática do etnógrafo, tal como aparece na antropologia da técnica e na etnomusicologia, passamos às narrativas sobre o engajamento em nossas próprias pesquisas. Elas lançaram mão de estratégias de integração e aprendizagem das atividades em dois cenários etnográficos muito distintos: o repente nordestino e duas modalidades de pesca amazônica. Em seguida a essas apresentações, e explorando a comparação entre elas, retomaremos algumas reflexões a respeito do engajamento enquanto forma de abordagem etnográfica.

\section{Etnografando em águas calmas e revoltas (por Carlos Sautchuk)}

Situada na região do estuário do rio Amazonas, a Vila Sucuriju (Amapá) apresenta dois grupos de pescadores especializados: um atuando na costa, em barcos motorizados com rede fixa ou espinhel de fundo; outro percorrendo a região de lagos, usando canoa a remo e arpão para capturar o pirarucu (Sautchuk, C. 2007). Logo no início da pesquisa de campo, uma série de sentidos diferentes e contrastivos apareceu, relacionada aos meios hídricos, aos peixes, às embarcações, aos artefatos. Objetos representativos das duas atividades, o arpão e o anzol recebiam grande ênfase: aquele era tido como parte do arpoador, sua extensão; já este, considerado um parceiro em grande medida autônomo, que captura o peixe no fundo, mas que pode "trair" e fisgar o próprio pescador. O mais relevante, para os propósitos de uma abordagem antropológica da técnica, é que isso tinha uma relação direta com o modo como os dois tipos de pescadores laguistas e pescadores de fora — consideravam sua atividade e a si mesmos. 
Se já era uma intenção prévia, o engajamento nas pescas tornou-se uma necessidade, pois o vínculo dos pescadores com suas atividades (os sentidos atribuídos à sua relação com os objetos técnicos, por exemplo) não dava mostras de poder ser compreendida exclusivamente por meio da observação dos comportamentos e das narrativas. Sem abrir mão destas, enquanto evidências empíricas e parâmetro de controle e reflexão sobre as categorias fundamentais da pesquisa, pareceu necessário ampliar o leque de possibilidades da etnografia. Sobretudo quando se desenhava mais claramente o valor de investigar o lugar do sujeito humano no interior desses processos técnicos - envolvendo animais, artefatos etc. — já que os processos de construção da pessoa ganhavam sentido conforme os engajamentos práticos dos pescadores. Isto fez com que outro aspecto se mostrasse importante - o aprendizado das atividades segundo os padrões locais (Sautchuk, C. 2005, 2013). Ou seja, não se tratava simplesmente de atuar junto, mas de inserir-se na dinâmica de aprendizagem própria a cada sistema, participando assim dos engajamentos técnicos que configuram as pessoas no lago e no mar. Seguem alguns exemplos do papel fundamental da prática nesta inserção etnográfica.

No caso do lago, foi apenas quando ocupei a popa da canoa, pilotando para um arpoador (ou proeiro), que pude efetivamente me dar conta do tipo de ambiente em que estava envolvido e de que maneira os laguistas o percorrem (Sautchuk, C. 2011). Até então, o lago parecia essencialmente uma superfície onde transitávamos livremente, apenas desviando da vegetação. Ao tomar o remo, devendo articular meus gestos aos do proeiro, implicado diretamente na orientação e na propulsão da canoa, pude perceber dois aspectos. O primeiro deles é que não há exatamente duas posições na canoa, pois o proeiro engloba completamente as ações do piloto. Este exerce bem seu papel quando faz de si uma extensão das capacidades, das ações e, sobretudo, das intenções do proeiro. Por isso, a troca do piloto enseja uma readaptação da mesma ordem que a substituição do arpão.

Para ficar num exemplo: no momento da arpoada, o gesto de remar (ou não) e de conter (ou não) a canoa contribui para a trajetória do arpão, incidindo diretamente na relação com o peixe — aspecto de vital importância — de maneira que o piloto pode inclusive ser "responsabilizado" por uma má arpoada. Conclusões dessa natureza provêm de uma percepção engajada nesse tipo de interação: encontram fundamento não apenas em minha própria experiência sensorial, mas também nos comentários emitidos sobre meu desempenho e nas conversas que tive a respeito dele com os pescadores.

Além desse englobamento dos gestos, que implica considerar o piloto incluído nas capacidades do proeiro, para entender a ação desse conjunto, 
é necessário pensar em algo semelhante a um campo operatório. Refiro-me a uma área em torno da canoa onde se projeta a virtualidade do corpo do arpoador, ou seja, um potencial de capacidades perceptivas e agressivas que em alguma medida compõe seu ser. Todos os outros seres também têm as suas projeções corporais, o que faz com que no lago, a rigor, não existam espaços vazios: a todo momento o laguista está em contato ou imbricado com o campo operatório de outros seres, de modo que visualizar primeiro é um imperativo de primeira grandeza, tanto pela vantagem estratégica quanto para não ser "mundiado", isto é, capturado pela visão de outro ser, seja ele um espírito, um peixe ou outro animal.

O fato de ter atuado no manejo desse campo operatório permitiu notar que termos aparentemente sinônimos - olhar, reparar e enxergar — remetem a modos de interação distintos. Uma preocupação constante, sobre a qual os laguistas me advertiam, é que há uma disposição da visão que não se limita apenas a olhar, ou seja, voltar a vista para uma direção. Em certas situações é necessário reparar, o que significa perscrutar o ambiente com intenção, com propósito, para que seja possível então enxergar, o que, num terceiro grau de intensidade das interações visuais, designa o ato de conectar-se visualmente com outro ser, com uma série de implicações. Para se deslocar bem através dos seres, num espaço onde não há propriamente vazios, mas somente imbricações, é mister perceber primeiro, o que significa navegar bem nessa gramática das disposições visuais recíprocas.

Entretanto, para perceber antes não basta conhecer o comportamento dos animais, mas deve-se entender a sensibilidade do animal sobre o comportamento do laguista. Após algumas demonstrações de minha inaptidão a respeito desse jogo de pontos de vista, Paroca, arpoador experimentado, pediu-me para mergulhar e, no fundo, quebrou um talo de vegetação. Em seguida me explicou que se nós, que não somos acostumados à vida submersa, somos alertados pelo ruído da quebra do talo, "imagina o pirarucu", acrescentando elogios à capacidade visual do peixe. Mergulhos e jogos aquáticos são, aliás, corriqueiros nas imediações das habitações nos lagos, numa espécie de inversão lúdica de posições, que envolve a experimentação de capacidades perceptivas e a imitação de comportamentos dos animais. Mas o mergulho de fato no fundo, nos locais de captura, para retirar um arpão preso, por exemplo, é temido. Essa exposição à realidade do fundo, em suas diferentes manifestações, possibilitou experimentar, em certo sentido, a reversibilidade potencial entre humanos e animais. É justamente por isso que, ao mergulhar e adotar uma disposição corporal que é semelhante à deste animal, ocupando o espaço do fundo, diz-se que o laguista se expõe inclusive ao risco de se transmutar em peixe. São carregados de drama os 
relatos feitos acerca disto, em que normalmente consta a intervenção de um pajé (cf. Sautchuk, C. 2007).

No que se refere ao manuseio do arpão, ao terem me dedicado em certas oportunidades o ensino diligente que os proeiros dispensam aos neófitos de sua parentela, a incorporação do artefato e a relação com o animal se mostraram fundamentais, mas de estatuto muito particular. Em primeiro lugar, ficou evidente que era necessário manejar o arpão como parte de mim mesmo, como um só corpo, a começar por arpoar mantendo o equilíbrio na canoa. Mas, justamente por isso, a habilidade com o arpão não é elaborada como a variável decisiva da eficácia da captura, mas como um a priori universal entre os proeiros. A destreza em si mesma não pode ser considerada o problema central nos lagos. Captura-se mais, ensinam os laguistas, não por habilidade com o arpão, mas por uma boa relação com o peixe.

Mesmo tendo chegado a empreender relação de captura com arpão apenas com peixes menores, foi-me possível perceber na arpoada certas propriedades aludidas de forma constante, porém fragmentada, pelos laguistas, que só pude realizar de fato quando tomei a arma em mãos. O mais significativo aprendizado disso foi a pertinência das afirmações de que é o peixe que se entrega, e não o arpoador que o submete. Inicialmente tomada por mim como elaboração metafórica (como de hábito na etnologia da caça), fui levado a perceber que tal assertiva desdobra-se a partir do próprio regime de interação entre arpoador e peixe. Afinal, após o lançamento, arma e animal se deslocam e para que eles se encontrem deve haver um movimento convergente. Assim, o proeiro considera que o desfecho de seus atos depende da imprevisível ação do peixe, não só quando ele ingressa em seu campo operatório, mas também quando se move em direção ao arpão. Quando isso ocorre, é sinal que o proeiro está "feliz para pirarucu". A experimentação do manejo encorporado do arpão e da interação "face a face" com o peixe ressaltaram o sentido da distinção que se estabelece nos lagos entre a relação com artefatos (como parte de si) e com animais (enquanto uma alteridade constitutiva).

Passando à pesca costeira, ressalto dois momentos significativos de minha inserção. Um deles ocorreu nos preparativos para meu primeiro embarque. O que seria uma atividade corriqueira mostrou-se um episódio repleto de preocupações e arranjos implícitos, quase secretos, entre diversas pessoas, para assegurar que eu teria a possibilidade de voltar a terra antes dos sete dias previstos inicialmente. $O$ forte contraste entre esse frenesi preparatório e a relativa desatenção que experimentei quando a bordo revela dois aspectos importantes dessa atividade. O primeiro deles é que a "disposição" para se adaptar ao impacto da vida a bordo é fundamental 
na constituição da pessoa do pescador - e tema de avaliação a cada embarque, mas sobretudo nos primeiros que, na falta de uma aprendizagem prévia, demonstram a propensão do neófito para o ofício. Ficara muito claro que o pescador vive entre dois planos distintos, apesar de complementares e relacionados - a casa e o barco - e que não cabe à família de um jovem acompanhar sua inserção na pesca, que se dá normalmente fora do círculo de parentes - exato oposto da atividade lacustre. Essa diferença implica um conjunto de relações materiais e corporais de ordem distinta.

Se não depende de um aprendizado longo e no interior do núcleo doméstico, como no lago, o engajamento na pesca costeira é, por sua vez, mais intenso e mais rápido (Sautchuk, C. 2005, 2013). A participação na atividade se dá antes mesmo que se tenha superado o mal-estar fisiológico, as dificuldades de equilíbrio, ou que se tenha dominado as habilidades para as principais tarefas. Na verdade, uma vez no barco, fui instado a integrar de imediato o circuito de atividades que compõe o serviço - lidar com as cordas, soltar e recuperar a âncora, operar o motor, puxar a linha, preparar anzóis e outros apetrechos, beneficiar o peixe etc. A exigência premente que o ritmo das ações impunha mostrava que os gestos individuais devem convergir para uma ação do todo - o barco. Apesar da relativa integração a bordo, as mãos ainda "por engrossar" (aspecto mais demorado da adaptação) eram sempre um limite a diversas atividades. Como tal, elas eram lembradas como um distintivo inequívoco de minha posição deslocada - mais próxima de professores e funcionários, diferentes dos pescadores feitos. Isto porque a "disposição" do pescador consiste justamente na capacidade de se transfigurar conforme as propriedades do sistema cinético a bordo, o que implica adaptações somáticas constantes e profundas. Não por acaso, suas qualidades (e defeitos) são referidas em termos de força, resistência, durabilidade atributos necessários à inserção num sistema intenso de relações cinéticas.

A conclusão mais interessante, quando tomados esses dois engajamentos de modo comparativo, é a do locus e do estatuto diferente das habilidades humanas em cada uma dessas atividades. Para o laguista se tornar um sujeito pleno - um arpoador, isto é, alguém apto a matar — precisa obviamente acoplar a si um aparato de percepção e de ação que inclui arpão, canoa e piloto. Mas a verdadeira questão surge a partir disso, quando sua independência dos outros humanos o coloca em face da sua dependência crucial das ações de um outro ser - o pirarucu. De modo que, se a destreza técnica é fundamental, ela só pode ser entendida como uma expressão desta relação mais ampla, que envolve a interação dialógica entre proeiro e peixe.

Já no caso dos pescadores costeiros, sua disposição para ir a bordo se comprova com a motivação para imergir completamente na dinâmica das 
atividades, isto é, o bom pescador não é exatamente aquele que traz (peixe), mas aquele que é ativo, capaz de se conectar e desconectar rapidamente em diferentes posições na rede de interações entre motor, maré, apetrechos, tripulação etc. Se quisermos circunscrevê-la, sua habilidade reside justamente em espalhar suas ações na dinâmica polivalente do serviço a bordo. Comparando as relações técnicas, poderíamos dizer que o proeiro se institui, conectando a si um conjunto de elementos, que o formam, e mantendo a partir daí uma relação em certo sentido dialógica com o peixe (relação que o reproduz). Já as habilidades do pescador possuem, digamos, um sentido difuso, pois ele tem seus atos e habilidades envolvidos em relações dispersas, em prol da composição das ações do barco, que é a entidade principal na costa.

O engajamento etnográfico nos processos de aprendizagem destas duas modalidades de pesca levou à percepção mais adequada do contraste significativo que se elabora localmente a respeito da constituição da pessoa em cada uma delas. Tornou-se claro, por exemplo, que não é possível abordar a relação entre pessoa e processos técnicos através da ênfase na ideia do domínio de uma habilidade técnica enquanto ação dos sujeitos humanos sobre os artefatos ou o ambiente. Porém, o modo como isto é colocado em questão pelas experiências práticas dos laguistas e pescadores é muito distinto.

\section{Improvisando versos entre a habilidade e a disputa (por João Sautchuk)}

Em minha pesquisa sobre o repente, também chamado de cantoria, ${ }_{1}{ }^{2}$ tinha como objetivo entender as maneiras pelas quais esse corpo de saberes e fazeres se reproduzia e como contribuía para a manutenção de certos valores em seu contexto de realização (Sautchuk, J. 2011, 2012). Para isso, de imediato pareceu necessário compreender o que faziam os repentistas e quais suas interpretações sobre seu fazer poético-musical.

A cantoria é uma arte poético-musical em que os cantadores têm que criar estrofes de improviso, isto é, no momento da apresentação. As apresentações ocorrem sempre em duplas, constituindo um diálogo poético em que os dois improvisadores se alternam na criação e no canto de estrofes, respondendo aos movimentos e às provocações um do outro e atendendo aos pedidos da plateia. Uma apresentação de cantadores envolve sempre parceria e disputa, podendo pender mais para um polo ou para o outro, a depender das disposições dos poetas e do público. Isto porque, ao mesmo tempo em que um repentista precisa sempre de um parceiro para criar e cantar seus versos, esse diálogo é entendido por eles e pela plateia como 
um enfrentamento. Esta dimensão fica mais explícita quando a dupla canta o desafio malcriado, em que um poeta faz troças, dirige ameaças fictícias ao parceiro e tece autoelogios exagerados. Porém, mesmo quando versam sobre a vida no sertão, amor, saudade ou qualquer outro tema, os dois poetas tentam convencer o público de sua superioridade no improviso poético sobre o colega. Esta disputa poética modula uma representação de valores de construção da masculinidade por meio do enfrentamento e da demonstração de coragem e dominância em face do parceiro de versos, na qual cada cantador coloca em risco sua honra e seu prestígio.

Para investigar os principais aspectos desse jogo agonístico, mostrou-se imprescindível entender o que é o improviso poético e como os poetas improvisam. Meu ponto de partida foi a constatação de que os cantadores elaboram suas estrofes em segundos, de acordo com rígidas e complexas normas de rima, métrica e coerência temática (chamada de oração), tendo como base, como orientação, o ritmo poético que incorporam desde a infância ao ouvir o repente no rádio e em apresentações.

O improviso é sempre relacional em dois sentidos. O improvisador se coloca em relação a padrões estéticos, conhecimentos e valores coletivos para criar novas mensagens, ao mesmo tempo em que se lança numa interação com outros sujeitos e fatores de uma situação social, e o improviso emerge como ação comunicativa nessa situação. Entendendo, portanto, que era preciso dar conta do processo criativo do cantador, e não apenas de seus resultados (os versos depois de cantados), optou-se por aprender a arte do repente desde o enquadramento prático dos repentistas e improvisando versos junto a eles. Essa estratégia de inserção etnográfica permitiu reunir fundamentos empíricos para afirmar que as toadas (as melodias sobre as quais os versos são improvisados) funcionam como espécie de fórmula verbal (Lord 2000) que comporta o ritmo peculiar de cada modalidade de estrofe e permite ao poeta criar novas mensagens dentro de padrões métricos tradicionais. Elas fornecem aos cantadores modelos e esquemas práticos para improvisação.

Entretanto, não foi fácil encontrar cantadores que se dispusessem a me aceitar como aprendiz, pois eles consideram a poesia um dom divino e inato e, portanto, não haveria como ensinar alguém a cantar repente. De modo geral, minha pretensão despertava nos poetas estranheza e incredulidade (expressas frequentemente em tom de zombaria), mas Zé Maria, veterano cantador residente em Fortaleza (Ceará), e Raulino Silva, jovem residente em Caruaru (Pernambuco), se comprometeram a auxiliar-me no aprendizado de sua arte.

No início do trabalho de campo, em Fortaleza, Zé Maria procurava ensinar as normas de métrica, rima e oração em seus detalhes por meio de explicações diretas. Cabia a mim criar e redigir estrofes, a partir das quais o 
mestre fazia correções de forma e estilo. Mesmo com estas riquíssimas lições de poética, eu me via ainda muito distante do propósito de cantar repente. Nesses encontros, Zé sequer me mostrou sua viola e nem esboçou intenção de me convidar para improvisar versos - talvez por não acreditar que eu fosse mesmo capaz de cantar repente.

Percebendo a grande distância existente entre o conhecimento das normas poéticas explicitadas pelos cantadores e as habilidades do improviso poético, procurei Raulino em Caruaru. Ele também dominava um conhecimento analítico-descritivo da cantoria, mas entendia que era necessário praticar. Assim, sua tentativa de me ensinar a cantar foi sempre por meio da prática: nós dois cantando versos de improviso com a viola em punho, mas sem plateia. Começou afinando e tocando viola para que eu acompanhasse e "pegasse" o ritmo, bem como cantarolando toadas de sextilha (a modalidade mais executada da cantoria) para que eu as aprendesse.

Na primeira "lição", Raulino cantou uma estrofe e em seguida iniciei cantando "Começo neste segundo / A aprender cantoria", mas demorei muito para criar e cantar os quatro versos restantes, que saíram bem mais tímidos e fracos. Seguiram-se mais algumas estrofes nessa dinâmica e, ao término, Raulino comentou: "você começou a [estrofe de] Sextilha grande como qualquer cantador, mas esmoreceu porque não tinha o que dizer no final". E enfatizou a necessidade de iniciar a criação de uma estrofe sempre pela queda, ou seja, os versos finais - é assim que todos os repentistas fazem. Isto facilita a composição ao amarrar a estrofe a uma ideia central e, no que diz respeito ao estilo, situa essa ideia central como clímax no desfecho da estrofe. Assim, Raulino oferecia, em meio à prática do repente, ensinamentos verbais de saberes teóricos, mediados, que eu já tinha escutado de outros cantadores. Porém, transformar o conhecimento dessa estratégia em uso sistemático, automatizado, foi um processo que levou meses. Durante alguns dias após aquela primeira lição, cantei junto a Raulino, o qual, por um lado, elogiou meu desempenho de iniciante e minha preocupação em manter a coerência dos versos, mas, por outro, criticou minha atitude tímida, cantando pra dentro, a voz acanhada e o cantar desentoado.

Desta forma, iniciei o aprendizado da cantoria no sentido inverso ao dos cantadores. Estes têm uma trajetória em geral muito semelhante. Ainda crianças, se interessam pela poesia ao assistirem a cantorias e ouvirem cantadores nos programas de rádio. Por meio dessa experiência, internalizam paulatinamente o ritmo poético, principal fundamento prático do repentismo, e passam a brincar de fazer versos, muitas vezes desafiando irmãos, primos e amigos. Se a criança ou jovem demonstra possuir o dom, acaba sendo incentivado pela família ou por algum cantador conhecido a se apresentar 
para plateias e, quiçá, tornar-se um profissional. É nesse momento posterior, quando já canta de improviso, que o noviço toma contato com as normas de rima e coerência, e com o conhecimento descritivo das estrofes que o ajudará a sofisticar suas habilidades.

Já o meu aprendizado do repente procedeu das regras e dos ensinamentos explícitos para o canto. Passei dois meses contando as sílabas para compor e escrever seguindo uma técnica ensinada por Zé Maria de bater os dedos de uma mão em sequências correspondentes aos ritmos dos versos. Isto forneceu uma intuição da métrica, uma noção do ritmo que, embora incipiente, auxiliou nas primeiras vezes em que cantei de improviso.

De regresso a Fortaleza, continuei praticando em casa, inventando sozinho assuntos ou desenvolvendo sobre temas que ouvira em cantorias. Concentrava-me em iniciar a composição de cada estrofe pela queda, e consegui impor-me esse hábito, o que tornou a composição mais rápida e ajudou a manter a coerência das estrofes. Contudo, naquele momento, ainda não havia percebido que a queda não é só a última linha, mas as duas últimas, formando uma frase completa, e isso embargava um pouco meu aprendizado. A partir da leitura de outros estudos, eu já sabia que toda sextilha de cantoria apresenta um padrão de divisão de seus seis versos em três frases de dois versos cada uma. Essa divisão é análoga ao padrão melódico das toadas, formadas por motivos (correspondentes aos versos) agrupados dois a dois em frases melódicas correspondentes às frases poéticas. Porém, até então, não atinava para isso quando compunha e pensava as estrofes verso por verso. Fica claro, portanto, a distância entre os conhecimentos analítico-descritivos (tanto nativos quanto acadêmicos) e o fazer da estrofe improvisada propriamente dita.

Foi então que reencontrei Zé Maria, disse-lhe estar praticando o improviso e que já tinha cantado versos com Raulino em Caruaru. Esta novidade propiciou outro patamar em minha relação de aprendizado com o repentista. Zé passou a me convidar para cantarmos em sua casa (sem plateia). Nessas sessões de repente, eu encontrava dificuldades para coordenar o dedilhar da viola, a atenção nos versos do parceiro e a composição do que ia dizer em seguida, pois cantar em dupla exige habilidades para coordenar a atenção que não são exigidas pelo treino solitário. E, ao contrário do que já conseguia fazer cantando sozinho, ao invés de pensar primeiro a queda, era o primeiro verso que me ocupava a atenção. Passamos a experimentar outras modalidades de estrofe, como o Mote (décima que deve ser concluída com uma frase poética dada de antemão que orienta o assunto e determina algumas rimas). Zé dizia-se surpreso com meu desempenho e estimou que em alguns meses eu poderia me apresentar em público fazendo participações em cantorias 
de outras duplas, mas alertou-me para no início cantar apenas com poetas conhecidos e confiáveis, para não passar humilhações.

Meses depois, comecei a me apresentar em público na Feira de Carua$\mathrm{ru}$, contexto menos formal e com ouvintes menos exigentes, e em cantorias, a convite dos poetas. Isto influenciou minha inserção em campo, e acabei ficando conhecido por muitos como repentista amador (alguns chegaram a afirmar a partir dali que eu possuía o dom da poesia), embora minha identidade de "pesquisador" (que possui valor peculiar para os cantadores) não tenha sido apagada. Ao cantar, recebia elogios por sempre dizer algo em cada estrofe, isto é, por preocupar-me com a coerência interna da estrofe e a concordância desta com o tema proposto. De fato, por ter iniciado meu aprendizado pela "teoria" (os discursos nativos acerca de métrica, rima e oração) e por ter esses fundamentos analítico-descritivos do repente como referência primeira, preocupava-me muito em conseguir cantar "certo" e em respeitar as regras da poesia. Acredito que isto tenha inibido meu desenvolvimento como cantador. Os elogios eram contrapostos por críticas e cobranças motivadas pela lentidão no canto das estrofes (consequência direta de uma demora na composição das mesmas), pela dificuldade em manter a afinação do canto e pelo pouco volume de minha voz.

Minhas limitações como cantador e principalmente as cobranças e as críticas sobre elas me chamaram a atenção para um aspecto fundamental da cantoria. Os cantadores enfatizam a mensagem poética como elemento central de sua arte $^{3}$ e privilegiam as normas de métrica, rima e oração na descrição de seu fazer. Se a poesia, em geral, se caracteriza pela construção de significados por meio de paralelismos e redundâncias sonoras (como as rimas e o ritmo uniforme dos versos), no repente, essas regularidades são intensificadas pelo canto que informa o ritmo poético, pelos toques das violas que sustentam o andamento da troca de versos e pela própria alternância dos dois repentistas na enunciação poética. Quer dizer, o significado da cantoria enquanto forma expressiva não está somente no conteúdo das mensagens linguísticas, mas se encontra também no todo formado por seus padrões estéticos. É essa sinergia que faz do verso cantado e sua performance um tipo especial de palavra entre outros gêneros de discurso. Um cantador não deve demorar demais para iniciar o canto de uma estrofe, nem gaguejar ou parar para pensar em meio a ela. Isto desagrada a plateia, pois quebra o ritmo do diálogo poético, ferindo a completude formada pelos diversos meios expressivos da cantoria.

Além disso, ficou claro que a lógica da interação da cantoria direciona as ações para a disputa entre os poetas. Certa vez, na Feria de Caruaru, cantei com um poeta com quem não tinha muita proximidade. Foi a primeira vez que cantei sem a complacência do parceiro. Na primeira sequência 
de estrofes, ele cantou sem hostilidade, mas com firmeza, não querendo dar chance para que um forasteiro o derrubasse na feira. Cantamos ambos agradando aos ouvintes, mas eu ganhava mais aplausos — sendo eu uma novidade, este fato foi comum em minha trajetória. Em seguida, perguntei a ele se poderíamos cantar uma determinada modalidade poética. Tentando lembrar a toada com segurança, demorei para iniciar a primeira estrofe, e ele irrompeu cantando outra modalidade. Como eu estava concentrado na composição de outra modalidade de estrofe, ainda inexperiente para lidar com esse tipo de adversidade, não consegui acompanhá-lo e parei a viola. Foi minha única decepção em público. Naquele fim de tarde, compreendi que ao cantar um poeta coloca em jogo sua imagem, e ele não se dispunha a arriscar a sua cantando com um (quase) desconhecido. Pode ser que ele tenha suposto que eu guardasse versos decorados e lançou outro gênero para evitar uma derrota. Ficou claro que a proteção dedicada a mim por outros parceiros em função da amizade e da confiança era privilégio que os poetas não costumam conceder uns aos outros.

Então, a disposição agonística dos poetas ficou aparente por meio de suas estratégias raramente verbalizáveis. O significado da disputa para o repentista e suas consequências na construção de sua imagem pessoal, de seu prestígio, de seu "nome", emergiram para mim com uma intensidade e uma complexidade que os discursos nativos não são capazes de fornecer. $\mathrm{O}$ curioso é que a partir dali desenvolvi um medo de "cantar atrás" (isto é, ficar em notável desvantagem em relação ao parceiro de versos) e de que minhas limitações como cantador chamassem mais a atenção que meus versos. De certa forma, acabei sendo absorvido pelas dinâmicas, os valores e os significados das interações entre os repentistas e destes com seus admiradores.

\section{Etnografias e engajamentos}

A comparação entre essas etnografias, tanto entre as duas modalidades de pesca amazônicas quanto entre estas e a cantoria nordestina, é central para o nosso argumento. Tal contraste evidencia que a defesa do engajamento do pesquisador como postura etnográfica não deve ser tomada como um pressuposto teórico a conduzir o encontro etnográfico. Não se trata, portanto, de defender a ação, a prática, contra o discurso ou a dimensão intelectual. Como foi evidenciado antes, através do comentário da abordagem etnográfica presente nos estudos sobre técnica e sobre música, o que gostaríamos de discutir a partir de nossas etnografias é uma questão da ordem do encontro etnográfico, mais do que um princípio teórico ou analítico a respeito das relações a serem etnografadas. 
Não se quer, evidentemente, estabelecer uma distinção entre teoria antropológica e método etnográfico, mas apenas apontar para o fato de que há assertivas que se dirigem prioritariamente a uma formulação abstrata, no nível conceitual, enquanto outras voltam-se sobretudo para os meios através dos quais é estabelecida e acessada a dimensão empírica numa etnografia. O exemplo da noção de "experiência" talvez esclareça melhor essa distinção. Este vocábulo situa-se provavelmente entre aqueles mais difundidos na antropologia contemporânea, espraiando seus sentidos entre dois polos, com diversas formulações nuançadas entre eles: a valorização da vivência do mundo das pessoas com quem se estuda, por um lado, e a noção de que a antropologia estaria fundada, e mesmo condicionada, à experiência subjetiva do pesquisador, por outro.

Também as etnografias aqui apresentadas são influenciadas por parte dos argumentos vinculados a esta noção, sobretudo aqueles associados à noção de prática e, de modo mais genérico, à influência da fenomenologia. Por exemplo, a ideia de que o conhecimento antropológico é relacional e situado é algo que informa de modo intenso nossas abordagens. Assim, do mesmo modo que os pescadores não falam de artefatos, mas das implicações entre eles e os artefatos, os cantadores não descrevem meramente cantorias, mas remetem a estratégias de posicionamento em seu interior. Isto tem implicações evidentes na forma de conceber a postura etnográfica que deseje abordar a pesca ou a cantoria em suas dinâmicas, pois envia às relações ou aos processos em curso e não apenas à narrativa sobre eles ou à observação que se pode fazer deles.

Nessa mesma direção, pode-se abrir um leque considerável de argumentos em favor da experiência como foco e meio da etnografia. Uma das formas com que ela tem sido defendida como método etnográfico atualmente segue a linha de uma aproximação fenomenológica, a exemplo da proposta de um empirismo radical formulada por Michael Jackson (1989):

Usando o corpo da mesma maneira que os outros, no mesmo ambiente, [o etnógrafo] encontra-se a si mesmo informado por uma compreensão que pode então ser interpretada de acordo com seus próprios costumes ou inclinações, ainda que ela permaneça baseada num campo de atividades práticas e que, portanto, permaneça em consonância com a experiência daqueles entre quem ele viveu (Jackson 1989:135).

Ingold (2000) e Pálsson (Pálsson 1993, 1994; Descola \& Pálsson 1996:06) aceitam as influências dessa forma de considerar a pesquisa de campo como imersão na vida local, através da noção de enskilment. Repensando a noção 
de tradução como fundamento do fazer antropológico, eles propõem que a etnografia, de modo geral, só é possível porque se dá através do envolvimento direto numa realidade comum, isto é, com o etnógrafo "imerso numa ação conjunta com seus companheiros de prática num ambiente compartilhado" (Ingold 1993b:222; cf. também Ingold 2000:167). Isto aponta diretamente para a aprendizagem — das atividades da vida local, não da cultura enquanto texto ou conhecimento antropológico — como forma de inserção etnográfica.

Outra abordagem etnográfica que explicita o emprego da vivência prática e da aprendizagem como métodos é aquela empreendida por Loïc Wacquant (2002), em estudo sobre boxeadores de um subúrbio de Chicago, no qual nos oferece uma associação particularmente elucidativa entre o aparato teórico de Bourdieu (1977), em especial a noção de habitus, ${ }^{4}$ e o universo dos boxeadores. Wacquant propõe então uma abordagem a partir do corpo, tendo este como instrumento de investigação e vetor de conhecimento, atitude que lhe permitiu possibilidades interpretativas inesperadas (2002:12, 89). Baseado em sua iniciação como boxeur, ele chega a uma série de valiosas conclusões a respeito da vida da população masculina praticante de boxe, conclusões estas que sublinham as formas de interação somática (sentidos, sensações, gestos), como um campo significativo na vida suburbana. Ele considera que

\section{[...] impõe-se que o sociólogo submeta-se ao fogo da ação in situ, que ele coloque, em toda a medida do possível, seu próprio organismo, sua sensibilidade e sua inteligência encarnadas no cerne do feixe das forças materiais e simbólicas que ele busca dissecar, que ele se arvore a adquirir as apetências e as competências que tornam o agente diligente no universo considerado... $(2002: 12) .^{5}$}

Desta forma, associada à valorização da experiência do etnógrafo, afirma-se também a opção deliberada pela aprendizagem de uma determinada prática como estratégia etnográfica privilegiada. A partir de uma convergência similar, considerando a aprendizagem como objeto e método da antropologia (Coy 1989), Marchand $(2008,2010)$ tem desenvolvido pesquisas e análises que provocam reorientações importantes nas abordagens cognitivistas acerca do conhecimento, ampliando-as para além do pensamento e da linguagem verbal, de modo a dar conta dos "fatores complexos e múltiplos que constituem qualquer campo de prática" (2010:S10, S11).

Contudo, ao tempo que aponta para valiosas abordagens na pesquisa etnográfica, esse campo de discussões suscita também alguma reflexão a respeito da noção de experiência. Parece ser necessário não encapsular o sentido deste termo, tão em voga nas vertentes neorromânticas da antropo- 
logia contemporânea (Duarte 2003, 2004) ${ }^{6}$, no valor da vivência individual enquanto meio de "tornar-se nativo". Afinal, isto seria ignorar o peso das diferenças, a começar pelas capacidades de percepção e ação, que são frutos de engajamentos não livremente agenciados. Parece-nos que, mesmo que ambos possam pescar ou cantar, etnógrafo e pescadores ou cantadores guardam inúmeras diferenças entre si. Por isso, talvez o fluxo numa espiral de aproximação/diferenciação, um aprofundamento necessariamente conjunto desse par, seja uma forma mais interessante de pensar a "experiência" de engajamento etnográfico. Acreditamos que a interação prática tem seu valor etnográfico na medida em que ela possibilita que contrastes sucessivos, e cada vez mais detalhados, de estatuto, de intenção, de envolvimento, de sentido e inclusive de competência numa dada prática sejam transformados em instrumentos heurísticos. A cada aproximação, uma miríade de novas distinções é revelada - trata-se da experiência não como fusão, mas como busca radical e progressiva dos contrastes. Trazendo para este debate a inspiração de dois preceitos dumontianos acerca da compreensão antropológica — seu caráter fundamentalmente comparativo e o movimento de aproximações sucessivas (Dumont 1985, 1997) - pode-se pensar o engajamento prático do etnógrafo como um recurso para (i) aproximar-se por meio da comparação e para (ii) comparar-se por meio da aproximação, de modo que a alteridade guarda aqui um valor preponderante. Nessa linha é que poderíamos falar plenamente do papel do erro ou do equívoco como expressão das diferenças e, portanto, como forma de conhecimento e de inserção etnográfica.

Por outro lado, o próprio contraste exercitado aqui entre as abordagens da pesca e da cantoria evidencia que não pretendemos fazer da experiência uma bandeira teórico-conceitual, encampando a defesa da prática ou da corporalidade em detrimento do intelecto ou da palavra. Nessa seara, especialmente, nota-se muitas vezes certa confusão entre os objetivos e os alcances de formulações de ordem eminentemente empírica com outras de caráter teórico. Assim, por exemplo, os argumentos a favor da noção de prática, podem estar se referindo, pelo menos, a um ou a vários desses aspectos: a) ações nativas enquanto problema e dado antropológico, b) representações locais sobre os fazeres enquanto foco da etnografia, c) abordagem pragmática dos discursos locais, d) antropologia enquanto prática intercultural com implicações mútuas, e) etnografia dos processos de transmissão de conhecimento.

Outro exemplo desse tipo de confusão potencial aparece em diversos trabalhos associados à antropologia do corpo, especialmente entre aqueles ligados à voga do embodiment. Diferentes críticos convergem ao observar que esta noção consiste na verdade num pressuposto abstrato, mais do que 
uma forma de acesso empírico à dimensão somática. Portanto, e afastando-se do que expressa como objetivo, o embodiment resultaria na permanência do tratamento do corpo a partir da dimensão semântica, simbólica, enfim, desincorporada (Connerton 1989:104; Jackson 1989:122; Ingold 2000:170). ${ }^{7}$

Seja como for, parece-nos razoável afirmar que o trabalho de campo implica, em qualquer situação, a inserção num determinado regime de práticas (não necessariamente fundado em competências circunscritas ao desempenho corporal) e a assunção de um papel nas relações locais. Entretanto, o aspecto crítico para nós é que o modo como este engajamento se estabelece reveste-se de importância vital para se considerar quais feixes de relações e quais tipos de interações humanas são o centro do esforço etnográfico. Da mesma maneira, a abordagem etnográfica da relação entre pescador, artefatos e animais, ou da disputa entre os repentistas diante do público, deve guiar-se não pelas afirmações teóricas a respeito das habilidades técnicas ou do fazer poético, mas pela forma como as relações estão postas em jogo e assumem relevância em cada uma destas situações. A investigação da interação perceptiva (no caso dos laguistas), das associações mecânicas (para os pescadores costeiros) ou das improvisações verbais como um jogo interativo (entre os cantadores) são escolhas epistemológicas influenciadas pelo conhecimento dos contextos e pela experiência prática das atividades que apontaram os diálogos teórico-conceituais mais relevantes. Aproximamo-nos assim de perspectivas que propõem uma compreensão artesanal da etnografia, que sintonize seus próprios modos de conhecimento com aqueles experimentados em campo (p. ex., Harris 2007).

Em suma, o que se pretende neste texto não é fazer estas duas pesquisas etnográficas convergirem para o elogio da etnografia enquanto práxis, mas sim, mais modestamente, refletir sobre a coerência entre meios e fins, entre a situação que se pretende etnografar e a maneira de se formular e elaborar a dimensão empírica de uma atividade. Isto aponta para a necessária multiplicidade não apenas dos temas e dos resultados, mas também dos modos de empreender o trabalho de campo, considerando formas alternativas de acesso a diferentes formas de experiência, derivando o fazer antropológico por searas que envolvem de maneira particular sentidos, percepções, gestos e palavras, na medida em que eles formam conjuntos de relações relevantes. Ademais, leva a sintonizar a abordagem etnográfica diante dos aspectos mais relevantes da realidade local.

Aspectos desta discussão foram tratados por Favret-Saada $(1977,2005)$ em sua conhecida reflexão sobre "ser afetado". A noção de afeto ilumina a partir de alguns ângulos o tema que estamos tratando, inclusive porque parece ser, por vezes e equivocadamente, reduzida à defesa da mobilização subjetiva 
(ou emocional) do pesquisador como modalidade privilegiada da etnografia ou, pior, como sua caução. Ainda que o envolvimento pessoal não esteja excluído do argumento de Favret-Saada, ela rejeita a defesa das sensações ou das experiências pessoais do etnógrafo como meio ou fim da etnografia.

Ao considerar a feitiçaria como um sistema de lugares, uma rede de comunicação - e não um conjunto de representações - ela afirma: "eu estava justamente experimentando esse sistema, expondo-me a mim mesma nele" (2005:158). Porém, continua a autora, não se trata de transformar o relato etnográfico num veículo subjetivo: "aceitar 'participar' e ser afetado não tem nada a ver com uma operação de conhecimento por empatia, qualquer que seja o sentido em que se entende esse termo" (2005:158). O ponto para Favret-Saada é que entre pessoas duplamente afetadas por uma mesma atividade se passam coisas que um observador participante, no sentido ortodoxo do termo (se é que isto existe...), está longe de poder acessar. O sentido forte da noção de "ser afetado", assim entendemos, está justamente na transposição para o fazer etnográfico daquilo que caracteriza a empresa antropológica: o ato de pôr em risco, de modo sistemático e intenso, seus próprios pressupostos, sobretudo aqueles acerca da etnografia (como engajamento e experiência). Para não restar dúvida, citemos mais uma vez:

Como se vê, quando um etnógrafo aceita ser afetado, isso não implica identificar-se com o ponto de vista nativo, nem aproveitar-se da experiência de campo para exercitar seu narcisismo. Aceitar ser afetado supõe, todavia, que se assuma o risco de ver seu projeto de conhecimento se desfazer. Pois se o projeto de conhecimento for onipresente, não acontece nada. Mas se acontece alguma coisa e se o projeto de conhecimento não se perde em meio a uma aventura, então uma etnografia é possível (Favret-Saada 2005:160, grifos nossos).

Argumentamos que postular o engajamento prático como estratégia etnográfica não significa uma defesa da experiência contra a razão, mas a proposta de que há modos diversos de conceber e de envolver-se com a empiria etnográfica. Também não se trata apenas de advogar um engajamento corpóreo, pois é necessário antes qualificá-lo do ponto de vista etnográfico o que é o corpo, afinal? Como vimos, na pesca lacustre foi preciso ingressar no jogo perceptivo entre arpoadores e peixes, enquanto na pesca costeira, o relevante esteve nas interações mecânicas a bordo. Já para a cantoria nordestina, foi importante, mas de alcance limitado, o estudo das normas poéticas e temas, pois o principal estava na execução do improviso, na arte de integrar-se de modo eficaz a uma situação específica de produção de sentidos verbais e de performá-los. 
Retornemos assim a uma afirmação corrente na antropologia, tão banal quanto crucial, de que é necessário submeter os dispositivos teóricos ao encontro etnográfico. Isto implica dizer que, mesmo quando se trata de defender a experiência como forma de etnografia, não se pretende afirmar sua forma, previamente, num sentido estrito, categórico, mas tomá-la em sentido indicativo, como uma postura de engajamento. Acreditamos que, por exemplo, a afirmação da importância do tácito, do corporal, da prática, da experiência é fundamental para desestabilizar certo logocentrismo, mas ela não pode constituir uma meta-narrativa, sob pena de comprometer a empresa etnográfica com um viés igualmente etnocêntrico, ainda que oposto. A relação entre o que se toma como corporal, inconsciente, prático com o que se considera no plano verbal, simbólico, imaginado deve também ser posto em perspectiva no plano etnográfico.

Assim como Evans-Pritchard (2005:244-245) defendeu que o etnógrafo deve adequar seu tema aos interesses locais, pareceu-nos que deveríamos também adequar a esse encontro nossos modos de relação empíricos e as estratégias conceituais deles decorrentes. Ou seja, da mesma maneira que etnógrafos são levados a tratar de gado numa circunstância e de bruxaria noutra, isto poderia levá-los a formas distintas de engajamento empírico e de elaboração sobre a etnografia nestas duas situações. Assim, se é certo que a pesquisa de campo não é apenas uma técnica de coleta de dados, mas um "procedimento com implicações teóricas específicas" (Peirano 1992:8), sendo por meio dela que a teoria antropológica se desenvolve e se sofistica, então parece importante não preestabelecer os meios e os termos da estratégia etnográfica. Parece-nos mais instigante pensar a experiência do antropólogo não como uma afirmação categórica e substantiva, mas como um esforço de intensificação e indeterminação dos engajamentos empíricos, potencializando assim os riscos à proposta de conhecimento requeridos para um efetivo diálogo epistemológico.

Recebido em 02 de junho de 2013

Aprovado em 13 de novembro de 2014

Carlos Emanuel Sautchuk é Professor do Departamento de Antropologia da Universidade de Brasília. Email: <cemanuel@unb.br>

João Miguel M. Sautchuk é Professor do Departamento de Antropologia da Universidade de Brasília. Email: <msjoaomiguel@gmail.com> 


\section{Notas}

${ }^{1}$ A noção de participação que discutiremos aqui se refere ao engajamento prático do antropólogo nas atividades que investiga. Nos distanciamos, evidentemente, da voga de "participação observante" que Cardoso (1986) criticou no contexto das ciências sociais brasileiras por não se acompanhar de uma crítica teórico-metodológica sobre as implicações dessa aproximação enquanto processo de conhecimento. Vale ressaltar ainda que, mais recentemente, surgiram valorosas reflexões, como as de Turner (2006) e Ramos (1999-2000, 2008), que, precisamente, investem nos ganhos epistemológicos do engajamento político entre antropólogos e grupos indígenas, mas que lidam com feixes de questões distintos dos que trataremos aqui.

2 O termo "cantoria" designa a arte do repente, a sua forma mais comum de apresentação e o campo social formado pelos cantadores e seu público. Seus poetas são chamados de repentistas, cantadores ou violeiros.

${ }^{3}$ Assim, um cantador é considerado grande em função das estrofes que cria e de sua capacidade de dar respostas surpreendentes diante de fatores diversos na situação de uma cantoria.

${ }^{4}$ A propósito, é interessante o comentário crítico de Wacquant (2007), dirigido aos usos e abusos da noção de habitus nas ciências sociais.

${ }^{5}$ Essas linhas foram, sem dúvida, inspiradoras para as abordagens da pesca e da cantoria que empreendemos. Não obstante, o próprio trabalho de Wacquant pode ser criticado por permanecer às vezes encapsulado nas vivências pessoais do pesquisador (somáticas, boa parte das vezes). Ou por não empreender uma reflexão mais detida a respeito da concepção de subjetividade e de corpo que informa seu trabalho e termina por orientar decisivamente o tom da etnografia.

${ }^{6}$ Ressaltando a importância da experiência enquanto problema etnográfico, Duarte (2003: 179) pondera que "há hoje, todavia, uma amplamente disseminada disposição em privilegiar a 'ação', a 'prática' ou a 'agência' no jogo social, em detrimento das análises que partem das ideias, representações ou categorias de pensamento. Essa disposição faz parte de uma retomada muito generalizada do 'romantismo' em combinação complexa com o 'empirismo', em oposição à longa preeminência do universalismo (sobretudo em sua versão estruturalista) no pensamento do século 20." Concordando com o autor, pensamos que não é o caso de defender uma dimensão em detrimento da outra, mas de pensar na adequação entre os interesses antropológicos e os meios de aproximação etnográfica.

${ }^{7}$ Um balanço crítico a respeito das potencialidades e limitações da influência fenomenológica na recente afirmação do corpo como tema das ciências sociais pode ser visto em Varela (1994). Na antropologia, veja-se, por exemplo, Farnell (1994) e Warnier (1999), que além das reservas apresentam também propostas alternativas para uma aproximação etnográfica do corpo, assim como Ingold (2000). 


\section{Referências bibliográficas}

BAILY, John. 2001. "Learning to perform as a research technique in ethnomusicology". British Journal of Ethnomusicology, 10(2):85-98.

BERT, Jean-François (ed.). 2012. "Les techniques du corps" de Marcel Mauss, dossier critique. Paris: Publications de La Sorbonne.

BOURDIEU, Pierre. 1977. Outline of a theory of practice. Cambridge: Cambridge University Press.

BRINNER, Benjamin. 1995. Knowing music, making music: Javanese Gamelan and the theory of musical competence and interaction. Chicago: Chicago University Press.

CARDOSO, Ruth. 1986. "Aventuras de antropólogos em campo ou como escapar das armadilhas do método". In: (org.), A aventura antropológica: teoria e pesquisa. Rio de Janeiro: Paz e Terra. pp. 95-105.

CHAMOUX, Marie-Noelle. 1978. "La transmission des savoir-faire: un objet pour l'ethnologie des techniques?". Techniques et Culture, 3:46-83. . 1981. "Les savoir-faire techniques et leur appropriation: le cas des Nahuas du Mexique". L'Homme, 21(3):71-94.

CONNERTON, P. 1989. How societies remember. Cambridge: Cambridge University Press.

COY, Michael (org.). 1989. Apprenticeship: from theory to method and back again. Albany: Suny Press.

DESCOLA, Philippe. 1994 [1986]. In the society of nature: a native ecology in Amazonia. Cambridge: Cambridge University Press. .; PÁLSSON, G. 1996. "Introduction". In: . (orgs.), Nature and society: anthropological perspectives. Londres: Routledge. pp. 1-22.
DUARTE, Luiz Fernando Dias. 2003. "Indivíduo e pessoa na experiência da saúde e da doença". Ciência \& Saúde Coletiva, 8(1):173-183. . 2004. "A pulsão romântica e as ciências humanas no Ocidente". Revista Brasileira de Ciências Sociais, 19(55):5-19.

DUMONT, Louis. 1997 [1966]. Homo hierarchicus: o sistemas das castas e suas implicações. São Paulo: Edusp. . 1985. O individualismo: uma perspectiva antropológica da ideologia moderna. Rio de Janeiro: Rocco.

EVANS-PRITCHARD, Edward E. 2002. Antropologia social. Lisboa: Edições 70. . 2005 [1937]. Bruxaria, oráculos e magia entre os Azande. Rio de Janeiro: Jorge Zahar.

FARNELL, Brenda. 1994. "Ethno-graphics and the moving body". Man, 29(4): 929-974.

FAVRET-SAADA, Jeanne. 1977. Les mots, la mort, les sorts. Paris: Gallimard. . 2005. "Ser afetado". Cadernos de Campo, 13:155-161.

HARRIS, Mark. 2007. "Introduction: ways of knowing". In: M. Harris (org.), Ways of knowing: new approaches in the anthropology of experience and learning. Oxford: Berghahn. pp. 1-24.

HOOD, Mantle. 1960. "The challenge of 'bi-musicality'". Ethnomusicology, 4(2):55-59.

INGOLD, Tim. 1993a. "The reindeerman's lasso". In: P. Lemonnier (org.), Technological choices: transformation in material cultures since the Neolithic. London: Routledge. pp. 108-125. . 1993b. "The art of translation in a continuous world". In: G. Pálsson (ed.), Beyond boundaries: understanding, translation and anthropological discourse. Oxford: Berg. pp. 210-230. 
.2000. The perception of the environment: essays on livelihood, dwelling and skill. Londres e Nova York: Routledge.

JACKSON, Michael. 1989. Paths toward a clearing: radical empiricism and ethnographic inquiry. Bloomington: Indiana University Press.

LEMONNIER, Pierre. 1975. Production du sel et histoire economique: introduction du marais salant de guérande. Thèse de Doctorat, Université René Descartes - Sorbonne. . 1992. Elements for an anthropology of technology. Michigan: University of Michigan.

LEROI-GOURHAN, André. 2004 [1943]. Évolution et techniques I - l'homme et la matière. Paris: Albin Michel.

LORD, Albert Bates. 2000 [1960]. The singer of the tales. Cambridge: Harvard University Press.

MARANHÃO, Túlio. 1975. Náutica e classificação ictiológica em Icaraí, Ceará: um estudo em antropologia cognitiva. Dissertação de Mestrado, Universidade de Brasília.

MARCHAND, Trevor. 2008. "Muscles, morals and mind: craft apprenticeship and the formation of person". British Journal of Educational Studies, 56:245-71. . 2010. "Making knowledge: explorations of the indissoluble relation between minds, bodies, and environment". Journal of the Royal Anthropological Institute, (N.S.):S1-S21.

MAUSS, Marcel. 2003 [1934]. "As técnicas do corpo". In: Sociologia e antropologia. São Paulo: Cosac \& Naify. pp. 399-424. 2009. Techniques, technology and civilisation. New York, Oxford: Durkheim Press, Berghahn Books (edited and introduced by Nathan Schlanger).

MENEZES BASTOS, Rafael José de. 1995. "Esboço de uma teoria da música: para além de uma antropologia sem música e de uma musicologia sem homem". Anuário Antropológico, 1993:9-73.
PÁLSSON, Gisli. 1993. "Introduction". In: G. Pálsson (ed.), Beyond boundaries: understanding, translation and anthropological discourse. Oxford: Berg. pp. 1-40. . 1994. "Enskilment at sea". Man, 29: 901-27.

PEIRANO, Mariza. 1992. A favor da etnografia. Série Antropologia 130. Brasília: Universidade de Brasília, Departamento de Antropologia.

RAMOS, Alcida R. 1999-2000. "Anthropologist as political actor". Journal of Latin American Anthropology, 4(2)-5(1):172-189. . 2008. "Disengaging anthropology". In: D. Pole (ed.), A companion to Latin American anthropology. Oxford: Blackwell Publishing. pp. 466-485.

RIVAL, Laura. 1996. "Blowpipes and spears: the social significance of Huaorani technological choices". In: P. Descola \& G. Pálsson (orgs.), Nature and society: anthropological perspectives. London: Routledge. pp. 145-164.

SAUTCHUK, Carlos Emanuel. 2005. "Laguistas et pescadores: l'apprentissage de la pêche dans une région cótière de l'Amazonie (Vila Sucuriju, Brésil)". Techniques et Culture, 45:161-186.

. 2007. O arpão e o anzol: técnica e pessoa no estuário do Amazonas (Vila Sucuriju, Amapá). Tese de Doutorado, Universidade de Brasília.

. 2011. "Gestos, águas e palavras na pesca amazônica". Anuário Antropológico, 2010(2):83-105.

. 2012. "Cine-weapon: the poiesis of filming and fishing". Vibrant - Virtual Brazilian Anthropology, 9:406-430. . 2013. "Pesca e aprendizagem: gestação e metamorfoses no estuário do Amazonas (Ensaio fotográfico)". Amazônica: Revista de Antropologia , 5:502-519. . 2014. "Resenha de BERT, Jean-François (ed.). Les techniques du corps de Marcel Mauss. Dossier critique". Horizontes Antropológicos, 20:424-426. 
SAUTCHUK, João Miguel M. 2011. "Poetic improvisation in the Brazilian Northeast". Vibrant-Virtual Brazilian Anthropology, 8(1):260-290. 2012. A poética do improviso: prática e habilidade no repente nordestino. Brasília: Ed. UnB.

SEEGER, Anthony. 1980. "Pesquisa de campo: uma criança no mundo". In: Os índios e nós: estudos sobre sociedades tribais brasileiras. Rio de Janeiro: Campus. pp. 25-40. . 2004 [1987]. Why Suyá sing: a musical anthropology of an Amazonian people. Urbana and Chicago: University of Illinois Press.

SIGAUT, François. 1994. "Technology". In: T. Ingold (org.), Companion encyclopedia of anthropology: humanity, culture and social life. London: Routledge. pp. 420-459.

SILVERMAN, Carol. 1995. "Forum comments: 'learning to perform, performing to learn'". The Journal of American Folklore, 108(429):307-316. SILVERWOOD-COPE, Peter. 1990. Os Makú: povo caçador do noroeste da Amazônia. Brasília: Ed. UnB.

TITON, Jeff Todd. 1995. "Bi-musicality as a metaphor". The Journal of American Folklore, 108(429):287-297.

TURNER, Terence. 2006. "Anthropology as reality show and as co-production: internal relations between theory and activism". Critique of Anthropology, 26(1):15-25.

VARELA, Charles. 1994. "Harre and Merleau-Ponty: beyond the absent moving body in embodied social theory". Journal for the Theory of Social Behaviour, 24(2):1-19.

VATIN, François. 2004. "Mauss et la technologie". Revue du MAUSS, 23: 418-33.

WACQUANT, Loïc. 2002. Corpo e alma: notas etnográficas de um aprendiz de boxe. Rio de Janeiro: Relume Dumará.
. 2007. "Notas para esclarecer a noção de habitus". Revista Brasileira de Sociologia das Emoções, 6(16):5-11.

WARNIER, Jean-Pierre. 1999. Construire la culture matérielle: l'homme qui pensait avec ses doigts. Paris: PUF. . 2001. "A praxeological approach to subjectivation in a material world". Journal of Material Culture, 6(1):5-24. 


\section{Resumo}

Neste artigo, propomos uma reflexão acerca da etnografia, tendo como foco a aprendizagem e o engajamento do pesquisador nas práticas que pesquisa. Partindo das discussões sobre este tema na etnomusicologia e na antropologia da técnica, traçamos um diálogo entre as pesquisas de campo dos autores sobre repentistas na região Nordeste e pescadores na Amazônia. A partir de então são pensadas as implicações da inserção do antropólogo na atividade etnografada, vista não como um fim em si mesmo, mas como estratégia privilegiada para acessar conhecimentos e valores tácitos e irrefletidos, perceber as hierarquias entre diversos tipos de relações envolvidas no desempenho de uma atividade e analisar suas formas peculiares de aprendizagem. A comparação entre as etnografias da cantoria e da pesca não é trazida aqui para defender o privilégio epistemológico generalizado da prática, do corpo ou da experiência, em detrimento das estruturas, do discurso ou do pensamento. A própria comparação entre os engajamentos numa atividade eminentemente verbal e noutras que envolvem sobretudo habilidades perceptivo-motoras já nos distancia deste recorte. O engajamento é tomado aqui não como afirmação de princípio, mas como uma postura etnográfica maleável, capaz de favorecer a adequação entre as questões antropológicas e os regimes de abordagem empírica em situações particulares.

Palavras-chave Etnografia, Aprendizagem, Experiência, Antropologia da Técnica, Etnomusicologia.

\section{Abstract}

This article proposes a reflection on "ethnography", focusing on the researcher's learning of and engagement with research practices. Starting from discussions of this theme in ethnomusicology and in the anthropology of techniques, we trace a dialogue across the research fields of the authors among repentistas in the Brazilian Northeast and fishermen in Amazonia. Through this dialogue, we reflect on the implications of the anthropologist's insertion in ethnographic activity, which is not seen to be an end in itself, but a privileged means for accessing knowledge and tacit values, perceiving hierarchies among the diverse types of relations involved in the execution of an activity and analyzing peculiar forms of learning. The comparison between ethnographies of singing and fishing is not intended to affirm the epistemological privilege of practice, the body or experience over structures, discourse or thought. The very nature of the comparison, rooted in the engagements of an activity that is eminently verbal and another that mostly involves perceptive and motor abilities, distances our aim from this approach. Engagement is here understood not as a general principle, but as a malleable ethnographic posture, capable of adequately favouring the accomodation of anthropological questions and empirical regimes in specific situations.

Key words Ethnography, Learning, Experience, Anthropology of Techniques, Ethnomusicology. 